GU J Sci, Part C, 7(2): 372-382 (2019)

\author{
Gazi Üniversitesi \\ Fen Bilimleri Dergisi \\ PART C: TASARIM VE TEKNOLOJI \\ http://dergipark.gov.tr/gujsc
}

\title{
İnce Cidarlı U Çelik Profillerin Eksantrik Yük Altında Tek Bulonlu Bağlantılarının İncelenmesi
}

\author{
Yusuf DEMİREL ${ }^{1, *}$ Oğuzhan TÜYLÜOĞLU \\ ${ }^{I}$ Gazi Üniversitesi, Mühendislik Fakültesi, İnşaat Mühendisliği Bölümü, 06570, Çankaya/ANKARA \\ ${ }^{2}$ Teleses, Inşaat Firması, Çayyolu Mah., 06810, Çankaya/ANKARA
}

\section{Grafik/Tablo Özet}

\section{Makale Bilgisi}

Bașvuru: 27/03/2019

Düzeltme:23/04/2019

Kabul: 19/04/2019

\begin{tabular}{l} 
Anahtar Kelimeler \\
\hline Ince cidarlı çelik \\
Bulonla bağlantı \\
Eurocode \\
AISI \\
Eksantrik
\end{tabular}

Eksantrik

\section{Keywords}

Thin walled steel

Bolted connections Eurocode

AISI

Eccentric
$\mathrm{Bu}$ çalıșmada sırt sırta bağlanmış ince cidarlı C profilli elemanlarının ağırlık merkezlerinden uygulanan çekme kuvveti ile eksantrik davranış oluşturulmuştur. Üç farklı sac et kalınlığı, üç farklı bulon çapı ve üç farklı bağlantı geometrisi değişkenleri ile deneyler yapılmıştır. Deney sonuçları ile ilgili standartlarda verilen eşitliklerden elde edilen dayanımlar ve kopma modları karşılaştırılmıştır.

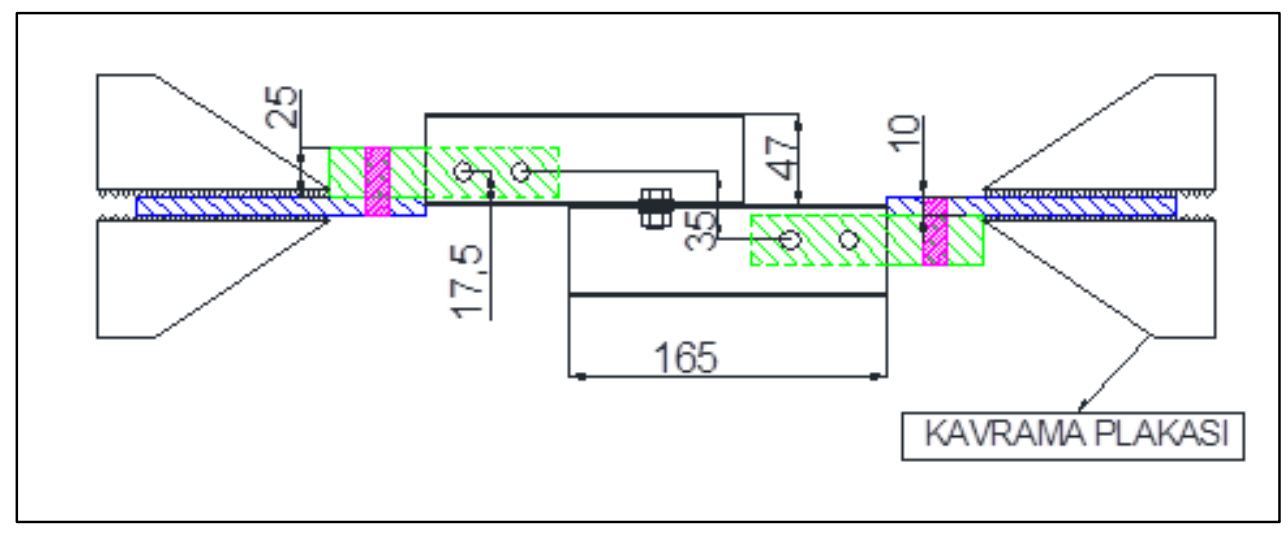

Şekil A. Örnek deney düzeneği

Amaç: $\mathrm{Bu}$ çalışmada literatür taramasında elde edilen deneysel çalışmalarda dikkate alınmayan eksantrik etki altında yapılan deneyler ile AISI ve EC standart eşitliklerinden elde edilen teorik dayanımlar ile deneysel dayanımlar karşılaştırılmak istenmiştir.

Teori ve Metod: Eksenel çekme yapabilen deney makinesi üretilen ek deney elemanları ile eksantrik çekme yapabilir duruma getirilmiş ve oluşturulan bu eksantrik etkinin literatür taramasında elde edilen çalışmalardaki güvenlik katsayılarından düşük sonuçlar elde edilmesi öngörülmüştür.

Sonuçlar: Deney sonuçları ile ilgili standartlarda verilen eşitliklerden elde edilen dayanımlar ve kopma modları karşılaştırılmıştır. AISI dayanımlarının EC dayanımlarına göre daha güvenli tarafta kaldığı, EC kopma modu öngörülerinin, AISI öngörülerine göre bu çalışmanın deneysel kopma modları ile sayıca daha fazla örtüştüğü tespit edilmiştir.

Değerlendirme: Elde edilen deneysel kopma yükü sonuçları sac kalınlıkları göz önüne alınarak incelendiğinde ise $\mathrm{t}=2 \mathrm{~mm}$ 'de deney elemanlarının diğer kalınlıklara göre standart öngörülerinden daha yüksekte kaldığı görülmüştür. Eksantrik etki altında ancak 9 farklı deney elamanı üstünde, 3 farklı profil et kalınlığı, bulon çapı ve bulon yerleşim geometrisine içerisinde sınırlı değişken aralıklarında gerçekleştirilmiştir. Çalışmada deneysel sonuçlar bu değişkenler içerisinde sınırlı aralıkta elde edilmiştir. Eksantrik etki altında ince cidarlı çelik profillerin bulonlu bağlantıların daha farklı et kalınlıklarında ve daha farklı bulon çaplarında irdelenmelidir. 
GU J Sci, Part C, 7(2): 372-382 (2019)

Gazi Üniversitesi
Fen Bilimleri Dergisi
PART C: TASARIM VE TEKNOLOJI
http://dergipark.gov.tr/gujsc

\title{
İnce Cidarlı U Çelik Profillerin Eksantrik Yük Altında Tek Bulonlu Bağlantılarının İncelenmesi
}

\author{
Yusuf DEMİREL ${ }^{1, *}$ Oğuzhan TÜYLÜOĞLU² \\ ${ }^{1}$ Gazi Üniversitesi, Mühendislik Fakültesi, İnşaat Mühendisliği Bölümü, 06570, Çankaya/ANKARA \\ ${ }^{2}$ Teleses, Inşaat Firması, Çayyolu Mah., 06810, Çankaya/ANKARA
}

\begin{abstract}
$\ddot{O} \mathbf{z}$
Makale Bilgisi

Başvuru: 27/03/2019

Düzeltme: 23/04/2019

Kabul: 19/04/2019

\section{Anahtar Kelimeler}

Ince cidarlı çelik Bulonla bağlantı

İnce cidarlı çelik elemanların bulon bağlantıları hakkında bir Türk standardı bulunmamaktadır. Eurocode ve AISI standartları dikkate alınarak yapılan hesaplamalarda aynı örnek için farklı yaklaşım ve davranış ortaya çıkmaktadır. Literatür taramasında elde edilen deneysel çalışmalarda eksantrik etki göz ardı edilmiş, yalnızca eksenel çekme altındaki davranış irdelenmiştir. Ancak uygulamada profil yapısından kaynaklanan eksantrik davranıştan kaçınılması mümkün değildir. Sırt sırta verilmiş ince cidarlı U profillerin tek bulon bağlantısı ile ağırlık merkezlerinden uygulanan çekme kuvveti uygulanması ile oluşturulan eksantrik davranış çeşitli sac et kalınlıkları $(\mathrm{t}=1,5 \mathrm{~mm}, 2 \mathrm{~mm}, 2,5 \mathrm{~mm})$ ve çeşitli bulon çapları $(\varnothing=8 \mathrm{~mm}, 10 \mathrm{~mm}, 12 \mathrm{~mm})$ altında ilgili standartlarda (AISI ve Eurocode) verilen eşitliklerden elde edilen kopma yükleri ve kopma modları karşılaştırılmıştır. AISI kopma yükü öngörülerinin Eurocode öngörülerine göre daha güvenli tarafta kaldığı, kopma modlarının öngörülmesinde ise Eurocode'un daha isabetli sonuç verdiği saptanmıştır.
\end{abstract}

Eurocode

AISI

Eksantrik

\section{Keywords}

Thin walled steel

Bolted connections

Eurocode

AISI

Eccentric

\section{Investigation of Single Bolted Connections of Thin Wall U Steel Profiles with Eccentric Behaviour}

\begin{abstract}
There is no Turkish standard for bolted connections of thin walled steel elements. In the calculations made according to Eurocode and AISI standards, there are different approaches and behaviours for the same sample. The eccentric effect was ignored in the experimental studies obtained in the literature review and only the behaviour under axial stress was examined. In practice, however, it is not possible to avoid eccentric behaviour arising from the profile structure. The eccentric behaviour created by applying the pulling force applied from the centre of gravity of thin walled $U$ profiles placed on back to back is compared with the strengths obtained from the equations given in the relevant standards under various sheet metal thicknesses $(t=1,5 \mathrm{~mm}, 2 \mathrm{~mm}$, $2,5 \mathrm{~mm})$ and various bolt diameters. $(\varnothing=8 \mathrm{~mm}, 10 \mathrm{~mm}, 12 \mathrm{~mm})$
\end{abstract}

\section{GİRIŞ (INTRODUCTION)}

İnce cidarlı çelik elemanların kullanımına Amerika Birleşik Devletleri ve İngiltere'de 1850 yılında başlanmıştır. Kullanım büyük ölçüde deneysel ve birkaç temel yapı ile sınırlanmıştır. 1980 yılından sonra Amerika Birleşik Devletleri'nde, artan ahşap fiyatlarından dolayı az katlı yapılarda hafif çelik elemanların kullanımı yaygınlık kazanmaya başlamıştır [1]. Güneş enerji yatırımlarının hız kazanması ve az katlı yapılara yönelim ile de ince cidarlı çelik yoğun olarak tercih edilmeye başlanmıştır [2]. Bu gelişmelerin ardından ülkeler kendi standartlarını oluştururken Türkiye'de ince cidarlı çelik elemanların bulon bağlantıları için bir teknik standart mevcut değildir. 
İnce cidarlı çeliğin kaynaklı birleşimleri malzemenin korozyon direncini düşürmekte, taneler arası korozyon, sigma fazı oluşumu kaynak sonrası sıcak çatlakların oluşması gibi birçok problemi peşinden getirmektedir. [3] Ayrıca işlemin yapılması için vasıflı işçilik ve elektrik gerekmekte bu da uygulamayı zorlaştırmaktadır.

İnce cidarlı çeliklerin bulonlu bağlantıları ise uygulamada yaygın olarak kullanılan bağlantı türlerinden biridir. Bulonlu birleşimlerin tasarım kuralları Amerikan ve Avrupa standartlarında ayrı konu başlıkları altında bulunmaktadır. Bununla birlikte, bu standartların tasarım kuralları, ince cidarlı çelik bulon bağlantılarının deneysel çalışmaları nispeten sınırlı olduğundan, ilgili bilgiler, normal çelik profil hesaplarının üzerinde ufak değişiklikler yapılarak temellendirilmiştir. Günümüze kadar ince cidarlı çeliklerin bulonlu birleşimleri üzerinde yapılan deneysel çalışmalar sınırlı olduğuna dikkat edilmelidir. Ayrıca, ince cidarlı çeliğin gerilme-şekil değiştirme davranışı, karbon çeliğinkinden temelde farklıdır [4]. Bu nedenle, ince cidarlı çeliğin bulon bağlantılarının yapısal davranışını incelemek önem taşımaktadır.

İnce cidarlı çeliklerin birleşim hesapları normal hadde profillerden ince cidarlı olması sebebiyle farklılıklar göstermektedir. AISI [5] ve Eurocode 3 Part 1-3'e [6] göre tasarımları incelenmiş ve uygulamalar yapılarak tasarım adımları gösterilmiştir. 1996'dan önce, Amerikan Demir ve Çelik Enstitüsü (AISI), ince cidarlı çelik yapı elemanları, birleşimleri ve montaj tasarımları için 2 ayrı standart yayımlamıştır. Bunlardan bir tanesi Emniyet Dayanımları Tasarımı metodu (ASD), diğeri ise Yük ve Dayanım Faktörü ile Tasarım metodudur (LRFD). Bu iki standart 1996'da tek bir standart olarak birleştirilmiştir. Özdeş tasarımlar üretmeseler de bu metotların ikisi de ince cidarlı çelik yapı elemanlarının tasarımı için kullanılmıştır. 2001 ve 2007 yıllarında Kuzey Amerika standardı yayınlandığında Kanada'da kullanılması için LSD yöntemi standarda eklenmiştir. ASD ve LRFD yöntemleri sadece Amerika ve Meksika' da kullanılmaktadır. Tasarım kuralları gerilmeler yerine dayanıma göre temellendirildiği için ASD yöntemi "güvenlik dayanımlarına göre tasarım" olarak yeniden tanımlanmıştır. [7]

Son yıllarda, yük ve dayanım faktörü tasarımı (LRFD) Amerika ve diğer ülkelerde çelik yapıların inşasında kullanılmaktadır. Yük ve dayanım faktörü tasarımının faydaları: (1) farklı yükler ve dayanımların belirsizlikleri ve çeşitliliği, çok sayıda katsayıyla hesaplanabilmektedir. (2) olasılık teorisi kullanılarak, tüm tasarımlar tutarlı bir güvenirlik kazanabilirler. Bundan dolayı, yük ve dayanım katsayılarıyla tasarım metodu, emniyet gerilmesi yönteminden daha güvenilir ve rafine bir tasarım temeli sağlar [7]. Eurocode için birleşimlerin tasarım kuralları ve koşulları için EN 1993-1-3'e bakılmalıdır. Standarttaki formüller 3 mm üzerindeki kalınlıkla için geçerli değildir. Seçilen deney elemanlarının kalınlığı $3 \mathrm{~mm}$ altında olduğundan bu standarttan faydalanılmıştır.

$\mathrm{Bu}$ çalışmada, ilk defa günümüze kadar ince cidarlı çeliklerin bulon bağlantıları için gerçekleştirilen çalışmalarda deney düzeneğine eklenmeyen dış merkezlik etkisi deney elemanlarına yansıtılmış, Avrupa ve Amerikan standartlarının öngörüleri ile deney sonuçları ile karşılaştırılmıştır.

\section{MATERYAL ve METOD (MATERIAL AND METHOD)}

İnce cidarlı çelik elemanların tek bulonla bağlantı hesaplarını incelemek amacıyla deneysel çalışma yapılmıştır. Yapılan bu çalışmada iki adet U profil çelik birbirine bulon ile bağlanıp kütle merkezlerinden yük aktarımı gerçekleştirebilen bir deney düzeneği deneye tabi tutulmuştur. Deney için tasarlanan elemanların boyutları, deneyde kullanılan ek parçalar (dış merkezlik oluşturabilmek için) ve örnek deney kurulumu Şekil 1 ve 2'de gösterilmiştir. U profilin imalatında kullanılan bükülme iç çapı TS EN 100252'den, $\mathrm{R}=\mathrm{t}$ olarak alınmıştır. [8] 


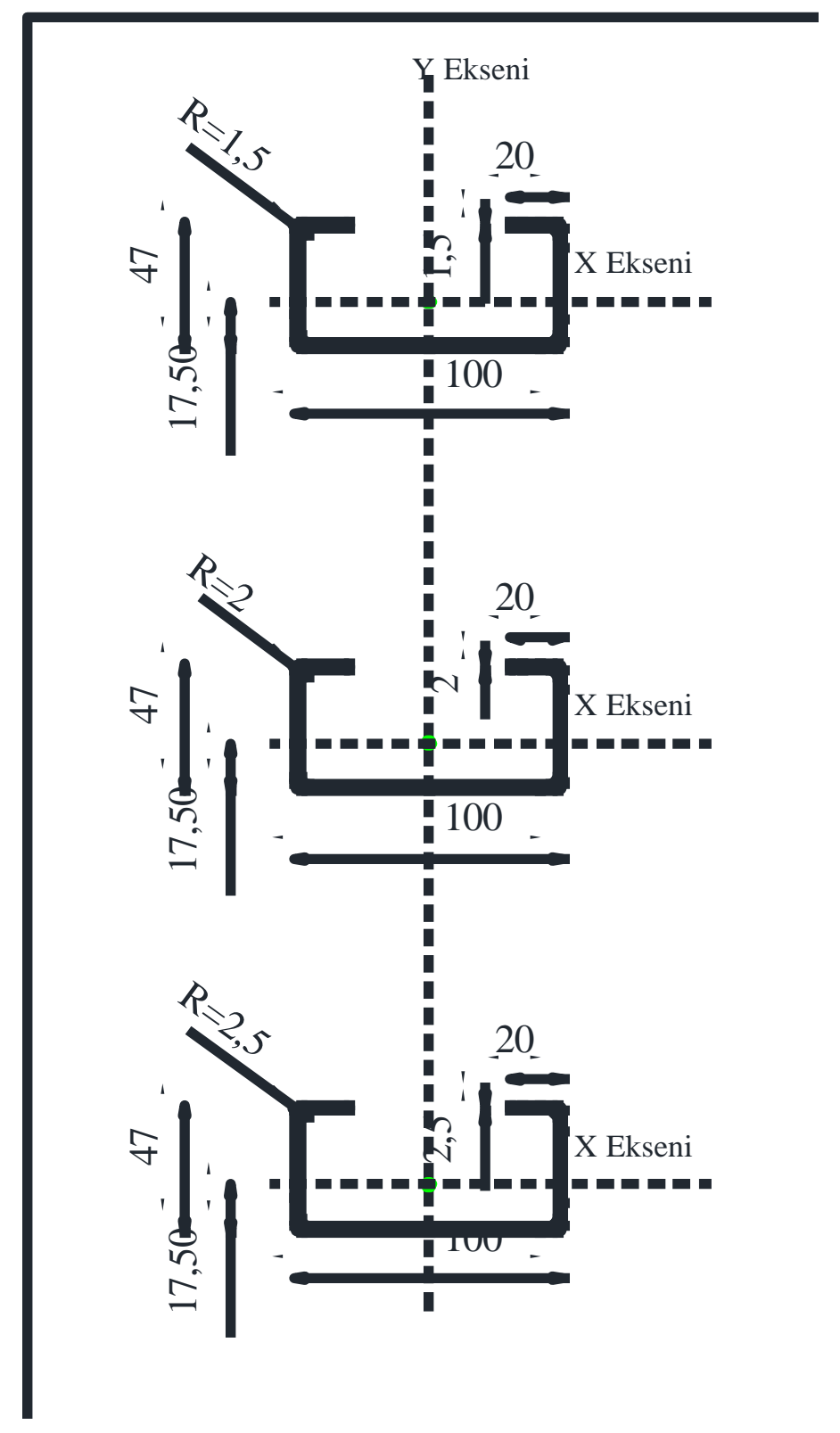

Şekil 1. U profil kesiti ( $\mathrm{mm}$ ) 


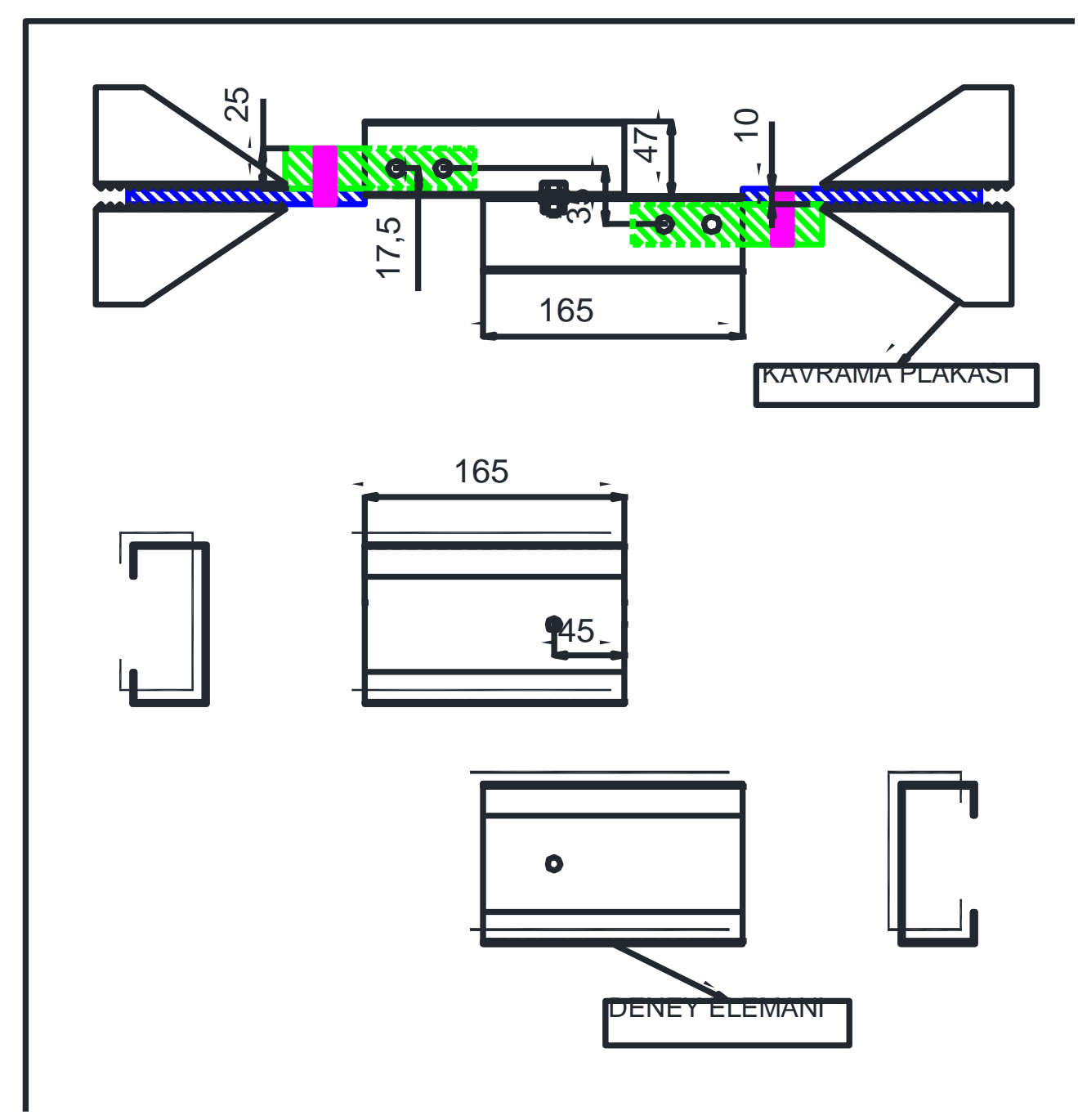

Şekil 2. Örnek deney düzeneği (mm)

Deneye tabi tutulacak elemanlar ilgili standartların; Eurocode [6] ve AISI [5] gereklerine göre tasarlanmıştır. Deney elemanları üç ayrı et kalınlığına $(\mathrm{t}=1,5 \mathrm{~mm}, 2 \mathrm{~mm}, 2,5 \mathrm{~mm})$ ve üç ayrı bulon çaplarının $(\emptyset=8 \mathrm{~mm}, 10 \mathrm{~mm}, 12 \mathrm{~mm})$ tüm olasılıklı irdelenmesini sağlayacak 9 farklı şekilde hazırlanmıştır. Deney elemanlarının malzeme, geometri, bulon çapı özellikleri Tablo 1'de gösterilmiştir.

Tablo 1. Deneye tabi tutulan deney elamanlarının özellikleri

\begin{tabular}{|c|c|c|c|c|}
\hline \multicolumn{5}{|c|}{ DENEY ELEMANLARININ MALZEME, BAĞLANTI GEOMETRISI, BULON ÇAPI } \\
ÖZELLIKLERI \\
\hline $\begin{array}{c}\text { Deney Eleman } \\
\text { Adı }\end{array}$ & $\begin{array}{c}\text { Sac Et } \\
\text { Kalınlı̆̆ }\end{array}$ & $\begin{array}{c}\text { Bulon Adedi ve } \\
\text { Yerleşim Geometrisi }\end{array}$ & $\begin{array}{c}\text { Bulon } \\
\text { Çapı }\end{array}$ & $\begin{array}{c}\text { Malzeme } \\
\text { Cinsi }\end{array}$ \\
\hline DE - 1 & $1,5 \mathrm{~mm}$ & Tek Bulon Yük Eksenine Dik & M8 & St 37 \\
\hline DE - 2 & $1,5 \mathrm{~mm}$ & Tek Bulon Yük Eksenine Dik & M10 & St 37 \\
\hline DE - 3 & $1,5 \mathrm{~mm}$ & Tek Bulon Yük Eksenine Dik & M12 & St 37 \\
\hline \hline DE - 4 & $2 \mathrm{~mm}$ & Tek Bulon Yük Eksenine Dik & M8 & St 37 \\
\hline DE - 5 & $2 \mathrm{~mm}$ & Tek Bulon Yük Eksenine Dik & M10 & St 37 \\
\hline
\end{tabular}




\section{DENEY ELEMANLARININ MALZEME, BAĞLANTI GEOMETRİII, BULON ÇAPI ÖZELLIKLERİ}

\begin{tabular}{|c|c|c|c|c|}
\hline $\begin{array}{c}\text { Deney Eleman } \\
\text { Adı }\end{array}$ & $\begin{array}{c}\text { Sac Et } \\
\text { Kalınlı̆̆ı }\end{array}$ & $\begin{array}{c}\text { Bulon Adedi ve } \\
\text { Yerleşim Geometrisi }\end{array}$ & $\begin{array}{c}\text { Bulon } \\
\text { Çapı }\end{array}$ & $\begin{array}{c}\text { Malzeme } \\
\text { Cinsi }\end{array}$ \\
\hline DE - 6 & $2 \mathrm{~mm}$ & Tek Bulon Yük Eksenine Dik & M12 & St 37 \\
\hline \hline DE - 7 & $2,5 \mathrm{~mm}$ & Tek Bulon Yük Eksenine Dik & M8 & St 37 \\
\hline DE - 8 & $2,5 \mathrm{~mm}$ & Tek Bulon Yük Eksenine Dik & M10 & St 37 \\
\hline $\mathrm{DE}-9$ & $2,5 \mathrm{~mm}$ & Tek Bulon Yük Eksenine Dik & M12 & St 37 \\
\hline
\end{tabular}

Çalışmada ince cidarlı çeliğin bulon bağlantılarına eksantrik yüklemenin etkisi incelenmiştir. Deneysel çalışma için eksenel çekme yapabilen deney düzeneğine sırt sırta bağlanmış U profiller üzerinde eksantrik davranışın oluşturulması amaçlanmıştır. U profilin alt tabakası ile bulon bağlantısının arasında kalan mesafe eksantrik uzaklığın yarısı, "e/2"yi ifade etmektedir. Diğer U profilin de bağlanması ile toplam eksantrik etkiyi oluşturacak "e" mesafesi oluşturulmuştur. U profillerin yan kanatlarından deney aparatlarına bağlanması ve ağırlık merkezlerinden uygulanan çekme kuvvetleri ile eksantrik davranış elde edilmiştir.
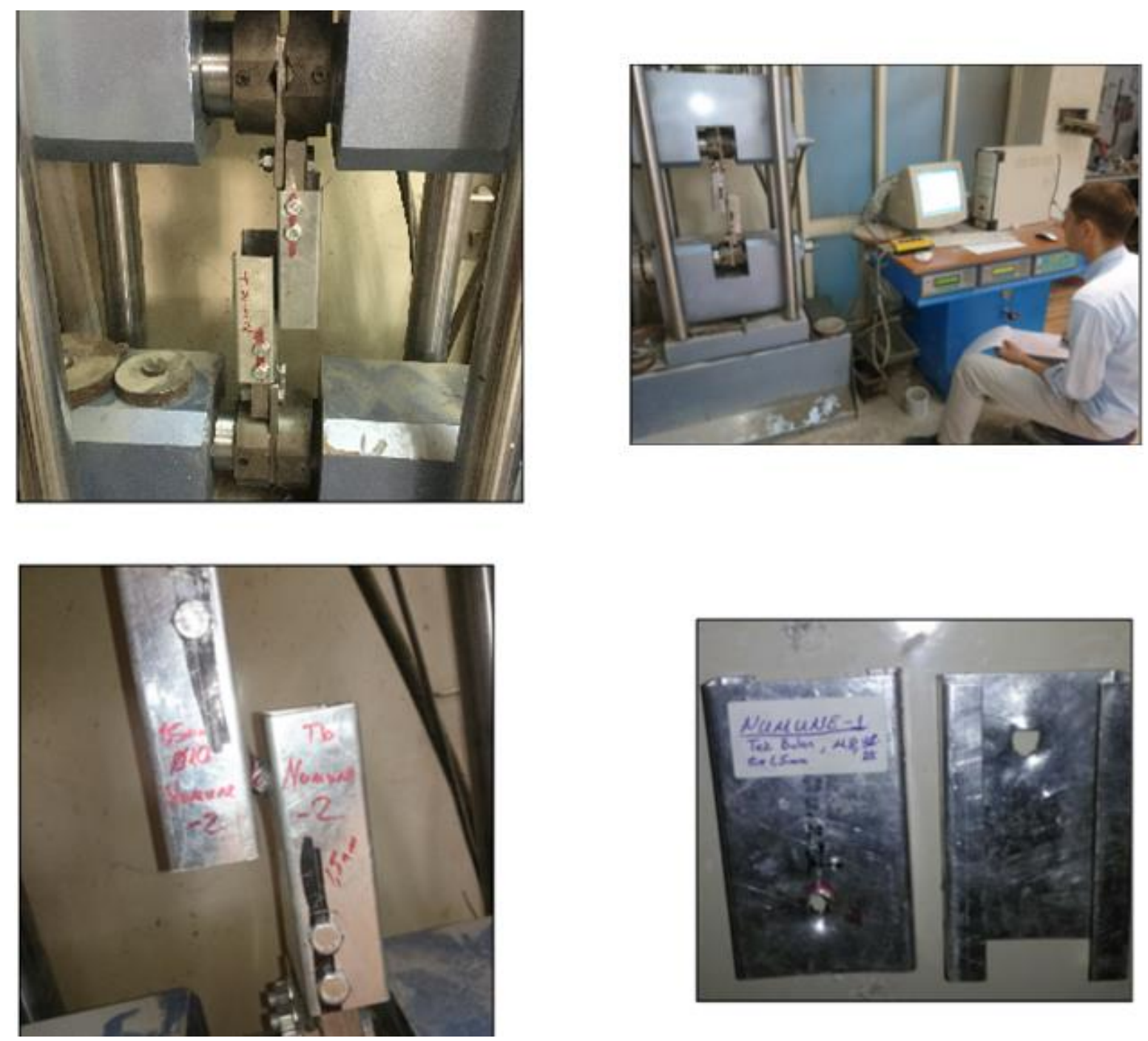

Şekil 3. Malzemenin deneye hazırlanmast ve deneyin yapılması 
Üretilen sacların delikleri laboratuvarda delinmiştir. Bağlantılardan doğru sonuç almak adına 8.8 kalite bulonlar gereken tork-metre değerlerine göre sıkılmıştır [9]. Hazırlıkları tamamlanan elemanlar Tablo 1'e göre adlandırılıp birbirine bağlandıktan sonra Şekil 3'te görülen deney elemanının deney öncesi yerine yerleştirilmesi, okumayı yapan bilgisayar destekli deney düzeneği, deney sonucu elde edilen kopma ve deney sonrası hali görülmektedir.

Deney aşamasında çekme düzeneğinin çalışmasını sağlayacak iki adet deney aparatı alttan ve üstten mesnetlemiştir. Uygulanan yük sonucunda elemanlarda meydana gelen yük-deformasyon verileri deney düzeneğine bağlı bilgisayar yardımıyla yük-deformasyon grafiği gözlenmiş, sayısal olarak da kaydedilmiştir. Deney aşaması bu grafikler ile sürdürülmüş, kayıt edilen veriler deney sonrasında yorumlanmıştır.

Deney elemanlarının ve düzeneğin hazırlanmasının ardından sırasıyla deneye tabi tutulmuştur. Deney elemanları deneyden önce, deney esnasında ve deneyden sonra fotoğraflanmıştır. Elemanlar makineye konduktan sonra önce elle tutturulmuş daha sonra makine yardımı ile hidrolik sıkıştırılmıştır. Bu sayede tutma kafalarında kaymanın önüne geçilmiştir. Uygulanan yük sonucunda elemanlarda meydana gelen yükdeformasyon verileri deney ekipmanına bağlı bilgisayar ile LVDT (doğrusal deplasman ölçer) yardımı ile okunmuştur. LVDT her yükleme öncesi kalibre edilmiştir. Kullanılan makine deformasyon/yük bilgilerini otomatik bilgisayar kontrollü bilgisayar programı ile \%1 hassasiyette ASTM E4-16'ya uygun olarak kayıt altına almıştır.

\section{SONUÇLAR ve TARTIŞMA (RESULTS and DISCUSSION)}

Tablo 1'de mekanik özellikleri verilen deney elemanlarının hepsi için deney gerçekleştirilmiş ve tüm kopmalar için yük/deformasyon bilgileri elde edilmiştir. Elde edilen sonuçlar Tablo 2'te verilmiştir.

Tablo 2. Deney sonuçları

\begin{tabular}{|c|c|c|}
\hline \multicolumn{3}{|c|}{ DENEY SONUÇLARI } \\
\hline Deney Eleman Adı & Kopma Yükü (KN) & Kopma Modu \\
\hline $\mathrm{DE}-1$ & 9,83 & Ezilme \\
\hline $\mathrm{DE}-2$ & 13,41 & Ezilme \\
\hline $\mathrm{DE}-3$ & 16,47 & Ezilme \\
\hline $\mathrm{DE}-4$ & 22,75 & Bulon Kopmas1 \\
\hline $\mathrm{DE}-5$ & 27,00 & Ezilme \\
\hline $\mathrm{DE}-6$ & 34,42 & Ezilme \\
\hline $\mathrm{DE}-7$ & 19,45 & Bulon Kopmas1 \\
\hline $\mathrm{DE}-8$ & 30,38 & Ezilme \\
\hline DE - 9 & 41,00 & Ezilme \\
\hline
\end{tabular}

U profil sacların standart eşitliklerinde kullanılmak için gereken çekme dayanımı (fu); profillerin üretildiği rulodan rastgele alınan her üç kalınlık için TS EN ISO 6892-1 [10] standardının Tablo B.1'deki şartları yerine getirilerek tayin edilmiştir. Saptanan bu dayanımlar standart eşitliklerinde kullanılmıştır. 
Tablo 3. Deneye tabi tutulan sacların çekme sinır gerilme değerleri

\begin{tabular}{|c|c|}
\hline \multicolumn{2}{|c|}{ U Profil Sacların Çekme Sınır Gerilmeleri } \\
\hline Sac Et Kalınlıkları & fu (MPa) \\
\hline \hline $\mathbf{1 , 5} \mathbf{~ m m}$ & 433 \\
\hline $\mathbf{2} \mathbf{~ m m}$ & 400 \\
\hline $\mathbf{2 , 5} \mathbf{~ m m}$ & 427 \\
\hline
\end{tabular}

Deneyi yapılacak ince cidarlı çelik U profil sacların birleşim kopma yükleri her bir tasarım için hesaplanmış ve ilgili standardın öngördüğü kopma modları ile belirlenmiştir. Beş farklı kopma modu için standartlar beş farklı hesaplama yöntemi ortaya koymuştur. Tablo 4'te, kopma modları altında EC olarak gösterilen sütun altında ilgili kopma modunun Eurocode eşitliğinden elde edilen teorik kopma yükü, AISI olarak gösterilen sütun altında ise ilgili kopma modunun AISI eşitliklerinden elde edilen teorik kopma yükü verilmiştir. Kalın olarak gösterilen değer ise ilgili deney elemanının kritik yüklemesini ifade etmektedir. Yani ilgili standart deney elemanın bu değerde ilgili kopma modunun gerçekleştireceğini öngörmektedir.

Tablo 4. Standartlardan elde edilen minimum kopma yükleri

\begin{tabular}{|c|c|c|c|c|c|c|c|c|c|c|}
\hline \multicolumn{11}{|c|}{$\begin{array}{l}\text { STANDARTLARDA VERİLEN EŞITTLİKLERDEN } \\
\text { ELDE EDİLEN DAYANIMLAR }\end{array}$} \\
\hline \multirow[t]{2}{*}{$\begin{array}{c}\text { Deney } \\
\text { Eleman } \\
\text { Adı }\end{array}$} & \multicolumn{2}{|c|}{$\begin{array}{c}\text { Levhanın } \\
\text { Akma } \\
\text { Dayanımı } \\
(\mathrm{KN})\end{array}$} & \multicolumn{2}{|c|}{$\begin{array}{c}\text { Levhanın } \\
\text { Yırtılma } \\
\text { Dayanımı } \\
(\mathrm{KN})\end{array}$} & \multicolumn{2}{|c|}{$\begin{array}{c}\text { Bulonların } \\
\text { Ezilme } \\
\text { Dayanımı } \\
(\mathrm{KN})\end{array}$} & \multicolumn{2}{|c|}{$\begin{array}{c}\text { Bulonların } \\
\text { Kesme } \\
\text { Dayanımı } \\
(\mathrm{KN})\end{array}$} & \multicolumn{2}{|c|}{$\begin{array}{c}\text { Net Kesit } \\
\text { Dayanımı } \\
(\mathrm{KN})\end{array}$} \\
\hline & $\mathbf{E U}$ & AISI & EU & AISI & EU & AISI & $\mathbf{E U}$ & AISI & $\mathbf{E U}$ & AISI \\
\hline $\mathrm{DE}-1$ & 51,4 & 46,2 & 22,4 & 19,6 & 9,9 & 8,9 & 14,1 & 15,2 & 16,7 & 19,6 \\
\hline DE - 2 & 51,4 & 46,2 & 22,4 & 19,6 & 12,4 & 11,2 & 22,3 & 23,7 & 19,0 & 19,1 \\
\hline DE - 3 & 51,4 & 46,2 & 22,4 & 19,6 & 14,9 & 13,4 & 32,4 & 34,2 & 21,2 & 18,7 \\
\hline 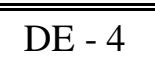 & 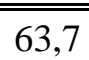 & 257,4 & 32,1 & 28,1 & $\begin{array}{c}14,3 \\
\end{array}$ & $\begin{array}{l}12,9 \\
\end{array}$ & $\begin{array}{l}14,1 \\
\end{array}$ & $\begin{array}{l}15,2 \\
\end{array}$ & 24,0 & 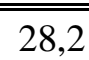 \\
\hline DE - 5 & 63,7 & 57,4 & 32,1 & 28,1 & 17,8 & 16,1 & 22,3 & 23,7 & 27,3 & 27,5 \\
\hline $\mathrm{DE}-6$ & 63,7 & 57,4 & 32,1 & 28,1 & 21,4 & 19,3 & 32,4 & 34,2 & 30,4 & 26,8 \\
\hline $\bar{~} \mathrm{DE}-7$ & 82,4 & "74,1 & "44,3 & 38,7 & 1919,7 & $\begin{array}{c}17,7 \\
\end{array}$ & ב14,1 & $\begin{array}{l}15,2 \\
\end{array}$ & 33,1 & 38 \\
\hline $\mathrm{DE}-8$ & 82,4 & 74,1 & 44,3 & 38,7 & 24,6 & 22,1 & 22,3 & 23,7 & 37,6 & 37,9 \\
\hline $\mathrm{DE}-9$ & 82,4 & 74,1 & 44,3 & 38,7 & 29,5 & 26,6 & 32,4 & 34,2 & 41,9 & 36,9 \\
\hline
\end{tabular}

Tablo 5'te ise "P $\mathbf{P}_{\text {exp }}$ " deney elemanının deneysel kopma yükünü, "P $\mathbf{P}_{\text {exp }} / \mathbf{P}_{\mathbf{E C}}$ " ve "P $\mathbf{P}_{\text {exp }} / \mathbf{P}_{\text {AISI" }}$ " ilgili deney elemanının deneysel kopma yükünün standart eşitliklerinden elde edilen teorik kopma yüküne bölünerek kıyaslanmasını ifade etmektedir. Deney sonuçları ile standart kritik kopma yükü oranları ve standartların kopma modu öngörüleri bu tabloda gösterilmiştir. 
Tablo 5. Deney sonuçları ile teorik sonuçların karşılaş̧tırılması

\begin{tabular}{|c|c|c|c|c|c|c|}
\hline \multicolumn{7}{|c|}{$\begin{array}{l}\text { DENEY SONUÇLARI İLE STANDART EŞITLİKLERINDEN } \\
\text { ELDE EDİLEN DAYANIMLARIN KARŞILAŞTIRILMASI }\end{array}$} \\
\hline \multirow{2}{*}{ Deney Eleman Adı } & \multirow{2}{*}{$\begin{array}{l}\mathbf{P}_{\text {exp }} \\
(\mathbf{K N})\end{array}$} & \multirow{2}{*}{$\begin{array}{c}\text { Kopma } \\
\text { Modu }\end{array}$} & \multirow{2}{*}{$\mathbf{P}_{\text {exp }} / \mathbf{P}_{\text {EC }}$} & \multirow{2}{*}{$\mathbf{P}_{\text {exp }} / \mathbf{P}_{\text {AISI }}$} & \multicolumn{2}{|c|}{ Öngörülen Kopma Modu } \\
\hline & & & & & EC & AISI \\
\hline DE - 1 & 9,83 & Ezilme & 0,99 & 1,10 & Ezilme & Ezilme \\
\hline DE - 2 & 13,41 & Ezilme & 1,08 & 1,20 & Ezilme & Ezilme \\
\hline DE - 3 & 16,47 & Ezilme & 1,10 & 1,23 & Ezilme & Ezilme \\
\hline DE - 4 & 22,75 & Bulon Kopmas1 & 1,62 & $1, \mathbf{5 0}$ & Ezilme & Ezilme \\
\hline DE - 5 & 27,00 & Ezilme & $\mathbf{1 , 5 1}$ & 1,68 & Ezilme & Ezilme \\
\hline DE - 6 & 34,42 & Ezilme & 1,61 & 1,79 & Ezilme & Ezilme \\
\hline DE - 7 & 19,45 & Bulon Kopmas1 & 1,38 & 1,28 & Bulon Kopmas1 & Ezilme \\
\hline DE - 8 & 30,38 & Ezilme & 1,24 & 1,37 & Ezilme & Ezilme \\
\hline DE - 9 & 41,00 & Ezilme & 1,39 & 1,54 & Ezilme & Ezilme \\
\hline & & Ort. & 1,32 & 1,41 & & \\
\hline
\end{tabular}

Elde edilen deney sonuçları ile standart öngörüleri karşılaştırılarak Şekil 4, 5 ve 6' da gösterilmiştir. Üç ayrı grafikte ilgili bulon çapında $t=1,5 \mathrm{~mm}, 2 \mathrm{~mm}$ ve $2,5 \mathrm{~mm}$ saclardan üretilen deney elemanlarının deneysel kopma yükleri ile Eurocode ve AISI standartlarından elde edilen kopma modu öngörüleri karşılaştırılmıştır. Şekillerde düz çizgi deney elemanlarının deneysel kopma yükünü, kesik çizgili Eurocode standart eşitliklerinin kritik kopma yükü öngörü değerini, noktalı çizgi ise AISI standart eşitliklerinin kritik kopma yükü öngörü değerini ifade etmektedir. Şekiller incelendiğinde $\mathrm{t}=2 \mathrm{~mm}$ saclardan üretilen deney elemanlarının kopma yüklerinin $\mathrm{t}=1,5 \mathrm{~mm}$ ve $2,5 \mathrm{~mm}$ saclardan üretilen deney elemanlarına göre standart öngörülerinden daha yüksek değerde olduğu görülmüştür. Standart eşitliklerinden elde edilen kopma yükleri aynı sac kalınlığında karşılaştırıldığında ise AISI eşitliklerinin Eurocode eşitliklerinden deneysel kopma yüklerine oranla daha düşük yakınsama göstermiştir.

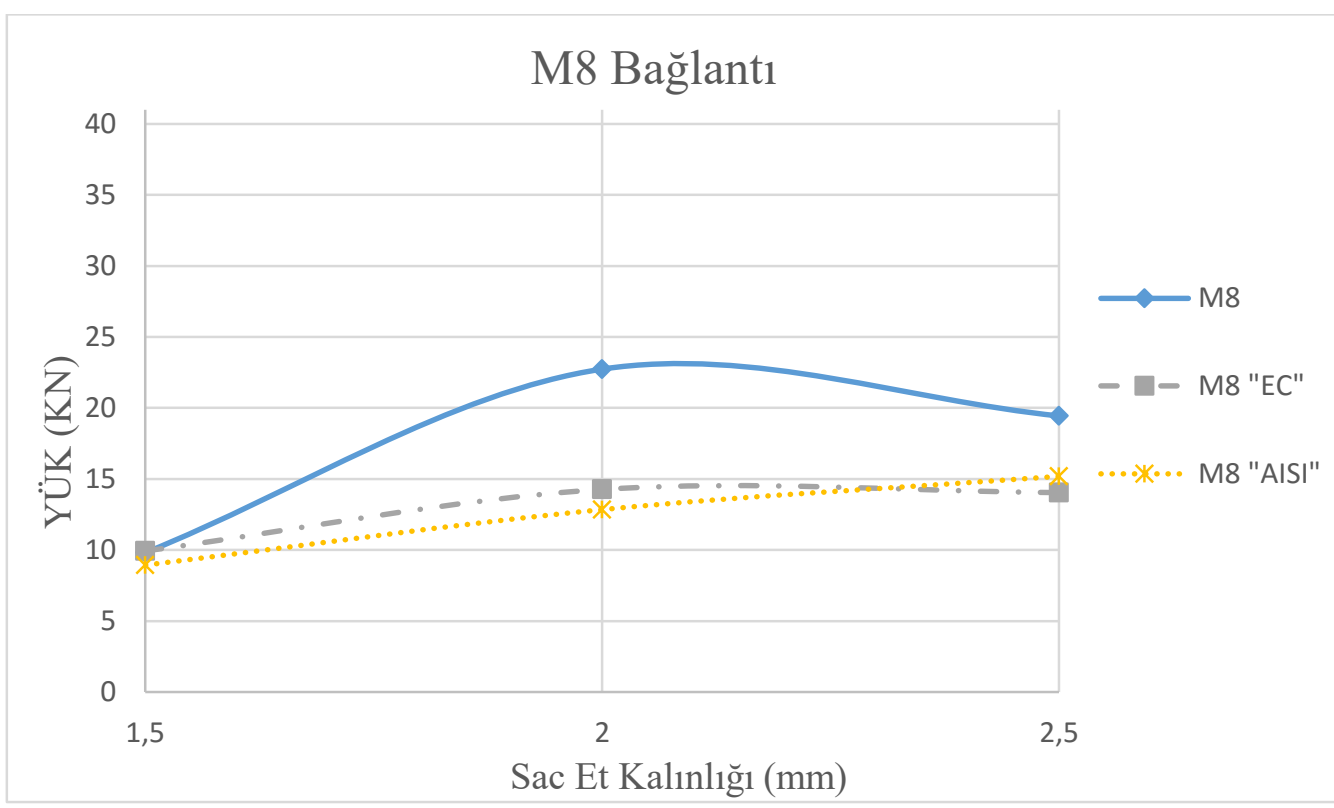

Şekil 4. DE 1-4-7 ile standart öngörülerinin karşılaştırılması 


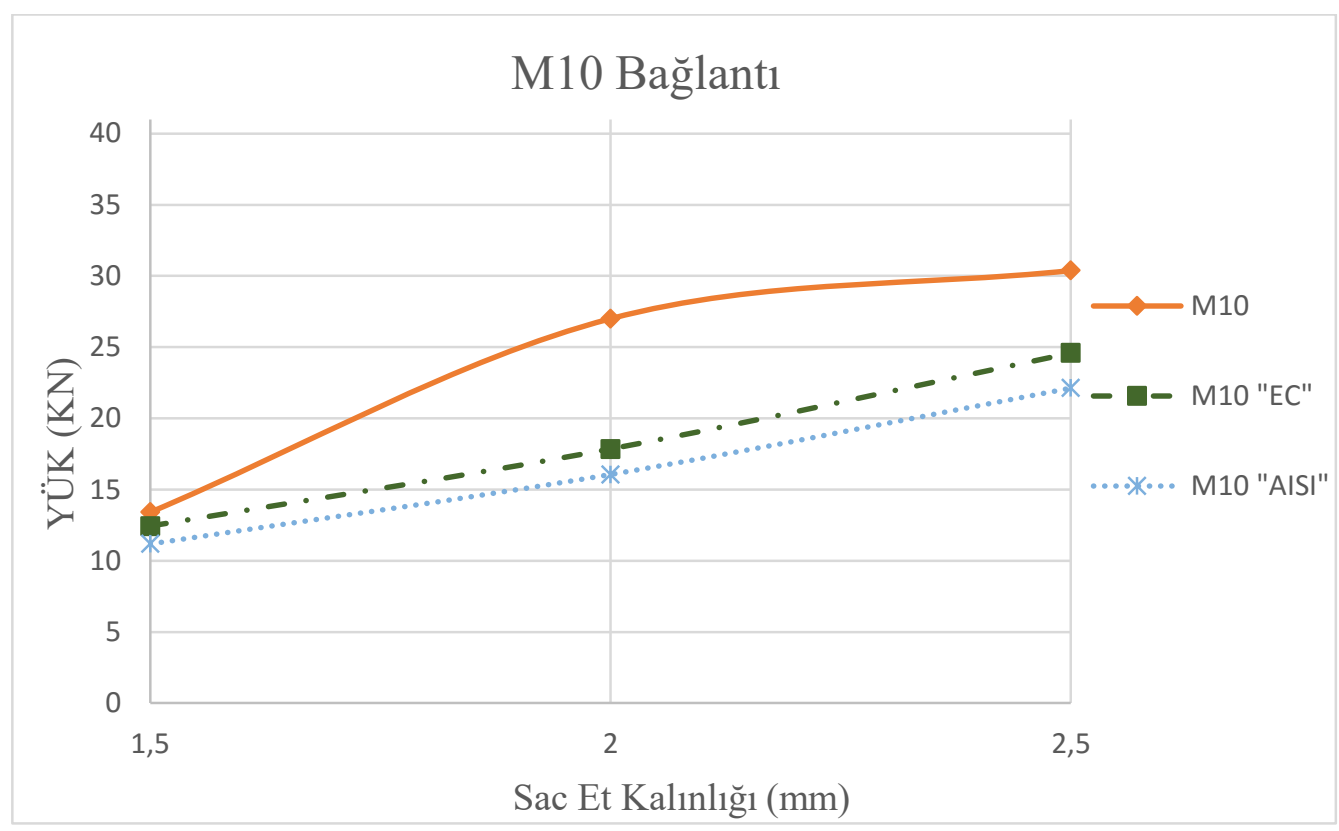

Şekil 5. DE 2-5-8 ile standart öngörülerinin karşılaştırılması

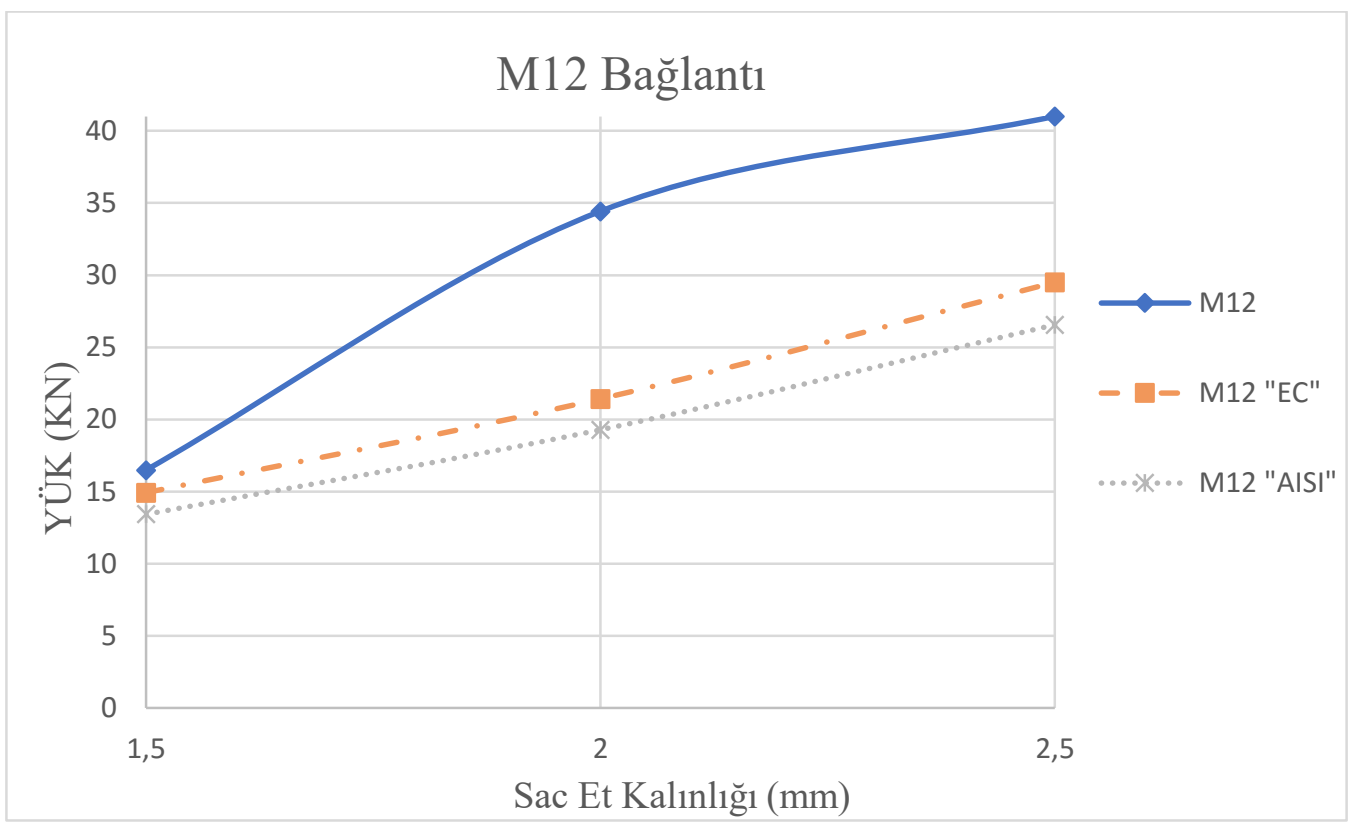

Şekil 6. DE 3-6-9 ile standart öngörülerinin karşılaştırılması

Deney elemanlarının üretildiği ince cidarlı çeliğin et kalınlığı ve bağlantıdan kullanılan bulon çaplarının arttırılması ile kopmayı gerçekleştiren yük miktarı artmıştır. Elde edilen deney sonuçları ile standart öngörüleri şekiller üzerinde karşılaş̧ırıldığında; deney sonuçlarının, deney elemanlarında kullanılan sac et kalınlığının ve bulon çaplarının lineer olarak arttırılmasına rağmen deney sonuçlarında lineer olmayan değişim tespit edilmiştir. Eksantrik etki altında yapılmayan "Yancheng Cai, Ben Young (2014)" [11] çalışmasına göre bu çalışmada daha düşük emniyet katsayıları elde edilmiştir. 


\section{SONUÇLARIN DEĞERLENDİRILMESİ ve ÖNERILER (ANALYSIS OF RESULTS AND RECOMMENDATION)}

Elde edilen sonuçlar irdelendiğinde AISI'nin kopma yük değerlerinin öngörülerinde daha güvenli tarafta kaldığı saptanmıştır. Kopma modlarının öngörülmesinde Avrupa standardı Amerikan standardına göre daha isabette sonuç vermiştir. Ortaya çıkarılan eksantrik etki ile "Soğukta İşlem Görmüş Paslanmaz Çeliğin Bulonlu Birleşimlerinin Yapısal Davranışı" "Yancheng Cai, Ben Young (2014)" çalışmasında ortaya çıkan dayanım katsayılarından daha düşük dayanım katsayılar elde edilmiştir. Elde edilen deneysel kopma yükü sonuçları sac kalınlıkları göz önüne alınarak incelendiğinde ise $\mathrm{t}=2 \mathrm{~mm}$ 'de deney elemanlarının diğer kalınlıklara göre standart öngörülerinden daha yüksekte kaldığı görülmüştür.

Eksantrik etki altında ancak 9 farklı deney elamanı üstünde test edilmiştir. Bu eki altındaki ince cidarlı çelik profillerin bulonlu bağlantıların daha farklı et kalınlıklarında ve daha farklı bulon çaplarında irdelenmelidir.

\section{KAYNAKLAR (REFERENCES)}

[1] U.S. Bureau of Labor Statistics, Producer Price Index by Commodity for Lumber and Wood Products: Lumber, https://data.bls.gov/timeseries/wpu08?data_tool=XGtable, (2018).

[2] G. Annageldiyev, "Soğukta Şekil Verilmiş Çelik Çerçeveli Duvar Panellerine Diyagonallerin Konması Halinde Yatay Yükler Altında Davranışı", Yüksek Lisans Tezi, Gazi Üniversitesi Fen Bilimleri Enstitüsü, (2009).

[3] Y. Özçatalbaş, G. Kuştutan ve U. Arabacı, AISI 304 Paslanmaz Çeliğin Nokta Direnç Kaynağında Birleştirmenin Mekanik Özelliklerine Soğuma Hızının Etkisi, Gazi Üniversitesi Fen Bilimleri Dergisi Part C: Tasarım ve Teknoloji, 6(2), 294-307, (2018).

[4] M. C. Akar, Sıcak Hadde Çeliği İle Soğukta Şekillendirilen Çeliklerin Özelliklerinin ve Taşıyıcı Farklılıklarının İncelenmesi, Yüksek Lisans Tezi, Yıldız Teknik Üniversitesi Fen Bilimleri Enstitüsü, (2010).

[5] AISI, North American Specification for Design of Cold-Formed Steel, Washington DC: American National Standards Institude, (2001), 1-98.

[6] Eurocode, " EN 1993-1-3, Eurocode 3 - Design Of Steel Structures - Part 1-3: General rules Supplementary Rules For Cold-Formed Members And Sheeting", European Committee for Standardization, Brussels, (2005), 1-67.

[7] W. W. Yu ve R. L. LaBoue, "Cold-Formed Steel Design (4rd Edition)", Rolla: Missouri University of Science and Technology, Missori, (2010), 1-272.

[8] TSE, "TS EN 10025-2, Sıcak Haddelenmiş Yapı Çelikleri - Bölüm 2: Alaşımsız Yapı Çeliklerinin Genel Teknik Teslim Şartları", Ankara, (2006), 25-28.

[9] Fastenal Company, Torque Calculator, https://www.fastenal.com/en/83/torque-calculator, (2018).

[10] TSE, "TS EN ISO 6892 - 1 Metalik Malzemeler - Çekme Deneyi - Bölüm 1: Ortam Sicaklığında Deney Metodu", Ankara, (2010), 1-41.

[11] Y. Cai ve B. Young , "Structural Behaviour of Cold Formed Stainless Steel Bolted Connections", The University of Hong Kong, Hong Kong, (2014). 